\title{
Grid voltage control by using DFIG during grid faults
}

\author{
Prof. Sushil Kumar ${ }^{1}$, Shilpa Manoj Rawte ${ }^{2}$ \\ $1_{\text {(Professor \& Head, EEE, Bhilai Institute of Technology, Durg) }}$ \\ (Asst. Professor, Electrical, Institute of Technology, Korba)
}

\begin{abstract}
This paper deals with the design of a voltage control strategy for DFIG wind turbines. The performance of the represented DFIG protection and control strategy during grid faults is assess and discussed by means of simulation of large DFIG wind farm connected to a power transmission system generic model .
\end{abstract}

Keywords:- doubly fed wind turbine, grid faults, power system control, voltage control

\section{INTRODUCTION}

This paper is organized as follows. First, the system configuration of DFIG-based wind turbines is presented with focus on the modeling and control issues relevant for a proper managing of grid faults. The power converter control is then explained, with focus on the aspects regarding fault ride-through and voltage control capability of DFIG wind turbines.

An aggregated model of a large offshore 160MW DFIG wind farm, implemented in the power system simulation toolbox MATLAB ( Simulink), is connected to a power transmission system generic model developed. The data for the wind turbines are not linked to any specific manufacturer, but are representative for the turbine and generator type used in variable speed DFIG wind turbines with pitch control. The interaction between the DFIG wind farm and the power system model during grid faults is assessed and investigated by means of simulations. The simulation results illustrate how the DFIG wind farm equipped with voltage control participates to re-establish properly the voltage during grid faults. The influence of the presented DFIG wind farm control setup on the performance of an active stall wind farm located nearby is also investigated.

\section{DFIG WIND TURBINE MODELING AND CONTROL ISSUES - IN CASE OF GRID FAULTS}

As a mainstream configuration for large wind turbines [5], DFIG wind turbines are required to remain grid connected during grid faults so that they can contribute to the stability of the power transmission system. This raises problems in terms of generator/converter protection and control. In the case of grid faults, the controllability of the DFIG variable speed wind turbine embraces both the wind turbine control for preventing over-speeding of the wind turbine and the control and protection of the power converter during and after grid faults [6].

Figure 1 sketches the main components of the DFIG wind turbine system configuration [6], [7]:

-Wind turbine - drive train, aerodynamics and pitch angle control system

- DFIG system - control and protection

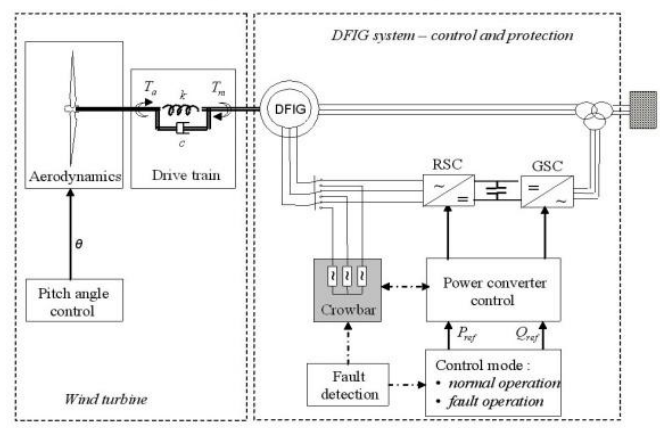

Figure 1: DFIG wind turbine - system configuration and control

2.1 Drive train, aerodynamics and pitch angle control system

In stability analysis, when the system response to heavy disturbances is analysed, the drive train system must be approximated by at least a two-mass model [8].

A two-mass mechanical model is used to get a more accurate response from the wind turbine during grid faults and to have a more accurate prediction of the impact on the power system. One mass represents the turbine inertia $J_{\text {rot }}$, while the other mass is equivalent to the generator inertia $J_{\text {gen }}$. These two masses are connected by a flexible low speed shaft characterised by a stiffness $k$ and a damping $c$, as described in [3]. It is also assumed a stiff high speed shaft and an ideal gear with the exchange ratio $1: n_{\text {gear }}$

The aerodynamic torque $T a$ from the rotor acts on one end of the drive train while the mechanical torque $T m$ from the generator side acts on the other end of the drive train - see Figure 1. The result of this is the torsion of the shaft. During grid faults, the electrical torque is significantly reduced, and therefore the drive train system acts like a torsion spring that gets 
untwisted. Due to the torsion spring characteristic of the drive train, the mechanical torque, the aerodynamical torque and thus the generator speed start to oscillate with the so-called free-free frequency:

$$
f_{o s c}=\frac{1}{2 \pi} \sqrt{\frac{k}{J_{e q}}}
$$

where $J_{e q}$ is the equivalent inertia of the drive train model , determined by:

$$
J_{e q}=\frac{J_{\text {rot } \cdot \eta_{\text {gear }}^{2} \cdot J_{\text {gen }}}}{J_{\text {rot }+\eta_{\text {gear }}^{2}+J_{\text {gen }}}}
$$

As these torsional oscillations may influence the converter operation both during grid faults and a short while after the grid faults have been removed, their modelling by using at least a two-mass model for the drive train system is essential. Furthermore, these torsional oscillations can even be excited and become undamped at a fast converter control [8].

A simplified aerodynamic model is sufficient to illustrate the effect of the speed and pitch angle changes on the aerodynamic power, during grid faults. This simplified aerodynamic model is typically based on a two dimensional aerodynamic torque coefficient $C_{q}$ table [3], provided by a standard aerodynamic program.

The pitch angle control, in Figure 1, is realised by a PI controller with antiwind-up, using a servomechanism model with limitation of both the pitch angle and its rate-of-change [6]. In the present work, the pitch angle control is implemented in such a way that the pitch angle controls the generator speed, i.e. the input in the controller is the error signal between the measured generator speed and the reference generator speed. In the case of over-speeding, the speed is controlled to its rated value, while the aerodynamic power is automatically reduced by increasing the pitch angle. This control is able to prevent over-speeding both in normal operations and during grid faults. The rate-of-change limitation for the pitch angle is very important during grid faults, because it decides how fast the aerodynamic power can be reduced in order to prevent over-speeding during faults. The dynamic stability of the generator is increased by the pitch angle control.

\subsection{DFIG system - control and protection}

A DFIG system is essentially a wound rotor induction generator with slip rings, with the stator directly connected to the grid and with the rotor interfaced through a back-to-back partial-scale power converter. The DFIG is doubly fed by means that the voltage on the stator is applied from the grid and the voltage on the rotor is induced by the power converter [3]. The converter consists of two conventional voltage source converters (rotor-side converter RSC and grid-side converter GSC) and a common dc-bus, as illustrated in Figure 1.

\subsubsection{DFIG control in normal operation}

The DFIG control structure, illustrated in Figure 2, contains the electrical control of the power converters, which is essential for the DFIG wind turbine behaviour both in normal operation and during fault conditions.

Power converters are usually controlled utilizing vector control techniques [9], which allow de-coupled control of both active and reactive power. The aim of the RSC is to control independently the active and reactive power on the grid, while the GSC has to keep the dc-link capacitor voltage at a set value regardless of the magnitude and the direction of the rotor power and to guarantee a converter operation with unity power factor (zero reactive power). As illustrated in Figure 2, both RSC and GSC are controlled by a two stage controller. The first stage consists of very fast current controllers regulating the rotor currents to reference values that are specified by a slower power controller (second stage).

The control performance of the DFIG is very good in normal grid conditions. DFIG control can, within limits, hold the electrical power constant in spite of fluctuating wind, storing thus temporarily the rapid fluctuations in power as kinetic energy.

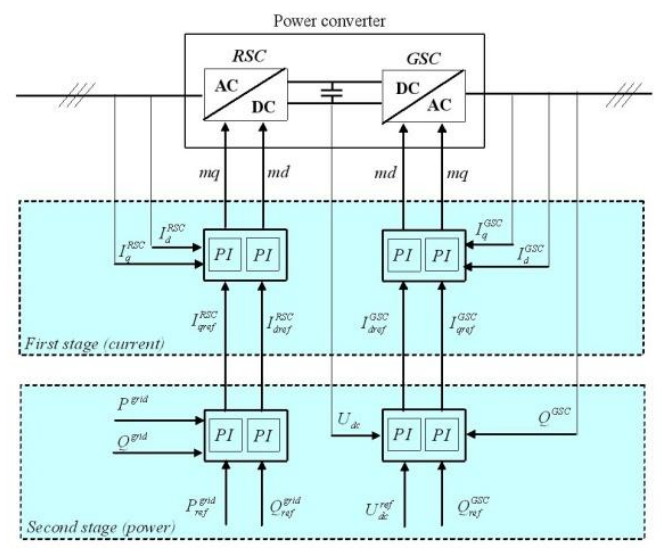

Figure 2: DFIG control structure - normal operation.

The active and reactive power set-point signals for the second stage controllers of the converters in Figure 2, are depending on the wind turbine operational mode (normal or fault operation) signals. For example, in normal operation:

- The active power set-point $P_{r e f}^{\text {grid }}$ for the rotor-side converter is defined by the maximum power tracking point (MPT) lookup table. 
- the reactive power set-point $Q_{r e f}^{\text {grid }}$ for the rotor-side converter can be set to a certain value or to zero according to whether or not the DFIG is required to contribute with reactive power.

- The grid-side converter is reactive neutral (i.e. $Q_{r e f}^{G S C}=0$ ) in normal operation. This means that, in normal operation, the GSC exchanges with the grid only active power, and therefore the transmission of reactive power from DFIG to the grid is done only through the stator

The dc-voltage set-point signal $U_{d c}$ is set to a constant value, independent on the wind turbine operation mode.

The use of the partial-scale converter to the generator's rotor makes DFIG concept on one hand attractive from an economical point of view. On the other hand, this converter arrangement requires advanced protection system, as it is very sensitive to disturbances on the grid.

\subsubsection{DFIG protection under grid faults}

Without any protection system, the concern in DFIG is usually the fact that grid disturbances can lead to large fault currents in the stator due to the stator's direct connection to the grid. Because of the magnetic coupling between the stator and the rotor and of the laws of flux conservation, the stator disturbance is further transmitted to the rotor. High voltages are thus induced in the rotor windings that on their turn cause excessive currents in the rotor as well. Furthermore, the surge following the fault includes a "rush" of power from the rotor terminals towards the converter.

Since the stator-rotor ratio of the DFIG is designed according to the desired variable speed range, in the case of grid faults it might not be possible to achieve the desired rotor voltage in order to control the high rotor currents, So when converter reaches fast its limits it looses the control of the generator during the grid fault [10]. As the grid voltage drops in the fault moment, the GSC is not able to transfer the power from the RSC further to the grid and therefore the additional energy goes into charging the dc bus capacitor, i.e. dc bus voltage rises rapidly.

A protection system of DFIG converter is thus necessary to break the high currents and the uncontrollable energy flow through the RSC to the dc-link and thus to minimize the effects of possible abnormal operating conditions. The protection system monitors usually different signals, such as the rotor current, the dc-link voltage and when at least one of the monitored signals exceeds its respective relay settings, the protection is activated.

A simple protection method of the DFIG under grid faults is to short circuit the rotor through a device called crowbar. The crowbar protection is an external rotor impedance, coupled via the slip rings to the generator rotor instead of the converter, as illustrated in Figure 1. The function of the crowbar is to limit the rotor current. When the crowbar is triggered, the rotor is short circuited over the crowbar impedance, the rotor-side converter (RSC) is disabled and therefore the DFIG behaves as a conventional squirrel cage induction generator (SCIG) with an increased rotor resistance. The independent controllability of active and reactive power gets thus unfortunately lost. Since the grid-side converter (GSC) is not directly coupled to the generator windings, there is no need to disable this converter, too. The GSC can therefore be used as a STATCOM to produce reactive power (limited however by its rating) during grid faults.

An increased crowbar resistance improves the torque characteristic and reduces the reactive power demand of the generator at a certain speed [10]. By the addition of the external resistance (crowbar resistance) in the rotor circuit during grid faults, the pull-out torque of the SCIG generator goes into the range of higher speeds. The dynamic stability of the SCIG generator is thus improved by increasing the external resistance [8].

Until a few years ago DFIG wind turbines were disconnected from the grid as soon as the crowbar protection was activated.

\subsubsection{DFIG control under grid faults}

In normal operation the active power set-point for the RSC control is defined by the maximum power tracking point (MPT) look-up table, as function of the optimal generator speed - see Figure 3. This means that for each wind speed there is only one generator speed resulting in maximum aerodynamic coefficient $C_{\mathrm{p}}$. However, in case of grid faults, the generator speed variation is not due to the wind speed change but due to electrical torque reduction. This means that, in the case of grid faults the active power set-point $P_{r e f}^{\text {grid }}$ has to be differently defined, i.e. as the output of a damping controller. Such a controller has as task to damp the torsional excitations which are excited in the drive train owing to the grid fault.

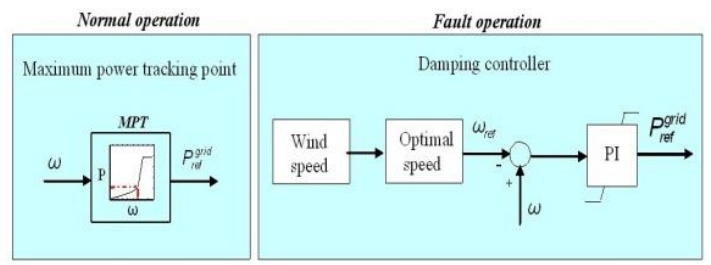

Figure 3: Definition of active power set-point for normal and fault operation, using MPT and damping controller respectively.

Different control schemes can be applied to damp these torsional oscillations. In this work suggested by [8] PI damping controller is used which produces the active power reference signal $P_{\text {ref }}^{\text {grid }}$ based on the deviation between the actual generator speed and its reference. The speed reference is defined by the optimal speed curve at the incoming wind. The damping controller is tuned to actively damp the torsional oscillations excited at a grid fault in the drive train system. [11] shows that absence or insufficient tuning of this PI controller may lead to self-excitation of the drive train system and to a risk of tripping as protection against vibrations in the mechanical construction. 
The pitch control system is not able to damp the torsional oscillations, because of several delay mechanisms in the pitch [12]. The pitch control damps the slow frequency variations in the generator speed, while the damping controller is able to damp the fast oscillations in the generator speed.

Figure 4 illustrates the effect of the damping controller in case of a 100ms three phase grid fault at the high voltage terminal of the 3-windings transformer of a 2MW DFIG wind turbine. It is assumed that the wind turbine works at its rated power at the fault instant. As the fault operation is small compared to the wind speed fluctuations, the wind speed can be assumed constant in the grid fault simulations. The generator speed and the mechanical torque are illustrated for the situations with and without damping controller respectively.

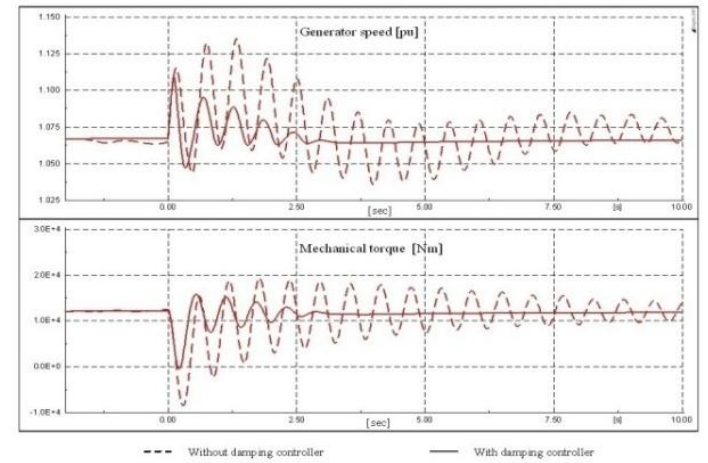

Figure 4: Damping controller effect.

Note that without the damping controller, the torsional oscillations excited by the grid fault are only slightly damped still 10 seconds after the grid fault incident. It is clearly visible that the oscillations are quickly damped over few seconds when the damping controller is used. Furthermore the amplitude of the mechanical torque is much smaller when using the damping controller. In contrast, when no damping controller is used, the mechanical torque crosses only once through zero when the damping controller is used, and therefore the mechanical stress of the drive train is substantially reduced in this case. The damping controller is thus minimizing the grid fault effect both on the mechanical and on the electrical side of the turbine. The protection system together with the damping controller enhances thus the DFIG fault overcoming capability.

During a grid fault, the tasks of RSC and GSC can be changed, depending on whether the protection system (i.e. crowbar) is triggered or not. In the case of less severe grid faults (i.e. not triggered crowbar) or reactive power unbalance in the system, the RSC and the GSC have the same tasks as in normal operation. In the case of severe fault (i.e. triggered crowbar), a specific grid support strategy has to be designed and developed.

\section{DFIG WIND TURBINE - GRID SUPPORT}

The technical specifications for the wind turbines, as defined by the power system operator, require wind turbines to behave as active components [13] and to support the grid. In this paper, the attention is mainly drawn to the DFIG voltage grid support during grid faults.

In general, different possible voltage control strategies exist for regulating voltage at the terminals of DFIG wind turbines. The voltage can hence be controlled by either the RSC [14] or the GSC [15] or by both of them [8]. There it is limited information in the literature about the latter voltage control method. The attention in this paper is therefore drawn to the voltage control strategy, where the reactive power contribution is performed by both converters in a co-ordinated manner. The idea is that the RSC is used as default reactive power source, while the GSC is used as a supplementary reactive power source during the blocking of the RSC.

At a severe grid fault, if the generator is not tripped, the DFIG wind turbine has to continue its operation with a short circuited generator, trying to sustain grid connection. When the crowbar is triggered, the RSC is blocked. In such situation, the RSC's controllability is lost and the DFIG grid support capability is thus strongly reduced. A solution to enhance the DFIG grid support capability during grid faults is to design a control strategy where the grid voltage (reactive power) control is taken over by the GSC. The GSC does not block at a grid fault, but it continues its operation as STATCOM as long as the RSC is blocked. When the crowbar is removed, the RSC starts to operate and the GSC is set again to be reactive neutral. The remove of the crowbar protection and hence the re-start of the RSC can be performed according different criteria, such as the magnitude of the grid voltage or of the rotor currents. A too soon RSC restarting may cause tripping of the converter again at the fault clearance.

As illustrated in Figure 5, the DFIG voltage grid support strategy is implemented in this work as an extension of the DFIG control structure used in normal operation and presented in Figure 2.

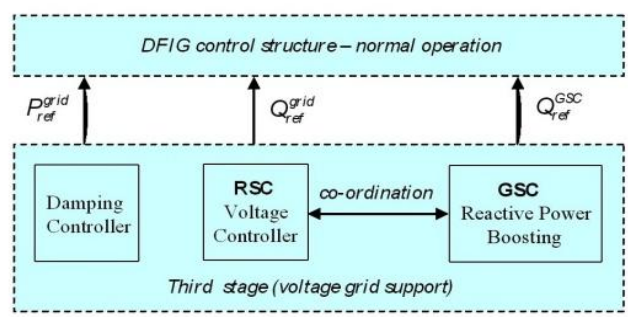

Figure 5: Extended DFIG control structure for voltage grid support during grid faults. 
An additional third control stage, having as task to improve the DFIG voltage grid support capability during grid fault, is thus added to the DFIG control structure used in normal operation [6]. This third (voltage) control stage, used in the case of fault operation and illustrated in Figure 5, provides the reference signals for the second stage controllers. This control stage contains three controllers, such as a damping controller, a rotor-side converter (RSC) voltage controller and a grid-side converter (GSC) reactive power boosting.

The damping controller, illustrated in Figure 3, is attenuating the oscillations in the drive train produced by the grid fault. It avoids an eventual wind turbine grid disconnection due to undamped oscillations in the generator speed.

The RSC voltage controller controls the grid voltage as long as the RSC is not blocked. The GSC reactive power boosting (a supplementary reactive power controller) generates a reactive power reference signal $Q_{\text {ref }}^{\text {grid }}$ for the GSC voltage control, in the case when RSC is blocked. The implemented reactive power boosting provides a zero reactive power reference when the RSC is active, and a maximum reactive power of the GSC (1p.u.) as reference value in the case when the RSC is blocked. This means that the GSC contributes with its maximum reactive power capacity for grid support under severe grid faults. As illustrated in Figure 5, a co-ordination between the RSC and GSC voltage control is implemented. During the grid fault, some of the controllers have to be disabled, while others are enabled. The enabling (start-up) of the controllers requires to be treated with some care to avoid discontinuities and to minimize the loads on wind turbines. Such discontinuities could eventually lead to prolonged transients and implicitly to subsequent operations of the crowbar protection.

\section{CASE STUDY}

In the following, a set of simulations are carried out in order to illustrate and evaluate the interaction, during grid faults, between a large DFIG wind farm and a realistic power transmission system model. It is assumed that, during the grid fault, the DFIG wind farm operates at its rated capacity, as this is worst for the voltage stability.

The goal of these simulations is to illustrate how the DFIG wind farm, equipped with the presented voltage grid support strategy, provides voltage grid support and how the DFIG voltage control affects the performance of a nearby active stall wind farm during the grid fault.

\subsection{Power system test model}

For this purpose, a power system model, similar to the small power transmission system test model developed in MATLAB ( Simulink), is implemented . The power system test model in its original form, as described in [16], is used in the present paper as basis for extension. The outline of the extended test model is presented in Figure 6 .

The generic power system model, in its original form described in [16], contains busbars with voltages from $0.7 \mathrm{kV}$ to $400 \mathrm{kV}$, four conventional power plants with their control, several consumption centres, a lumped equivalent for old onland local wind turbines and a model for a $165 \mathrm{MW}$ offshore wind farm, connected through a sea cable to the transmission grid of $135 \mathrm{kV}$. The conventional power plants are synchronous generators with primary voltage control.

The on-land local wind turbines are fixed-speed stall controlled wind turbines, equipped with no-load compensated induction generators.

The $165 \mathrm{MW}$ offshore wind farm is modelled as active stall controlled wind turbines with induction generators. This active stall offshore wind farm, is equipped with a fault overcoming capability control, which reduces the active power production in order to avoid uncontrolled over-speeding, in the case of a severe voltage drop. The reduction of the active power production implies that the reactive power absorption is reduced too. Such power reduction control has a positive effect, contributing to a better stabilisation of the wind farm. It is a kind of passive reactive power control as it does not participate actively in the voltage control of the system as shown in the simplified structure of power system model.

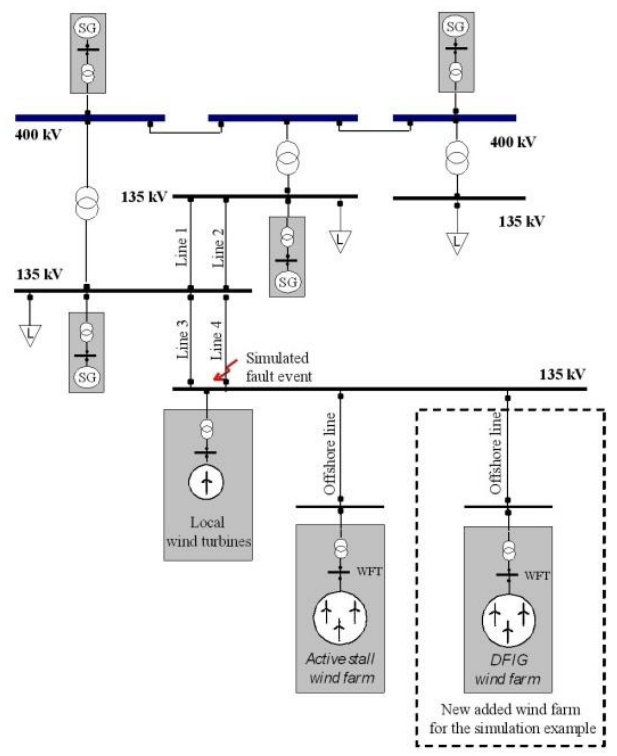

Figure 6: Simplified grid structure of the power system model. 
The power system test model, described in [16], is in this paper extended by connecting at a $135 \mathrm{kV}$ busbar an additional offshore wind farm, made up exclusively of 80 equal 2MW DFIG wind turbines. Similarly to the 165 MW offshore active stall wind farm, the new added offshore wind farm is modelled also by one machine approach based on the aggregation technique. It is assumed that the one DFIG turbine with re-scaled power capacity is modelled and equipped with the fault removing capability and the presented voltage grid support strategy.

\subsection{Simulation Results}

Two set of simulations are presented in the following. The first set illustrates how the DFIG wind farm provides voltage grid support, while the second shows how the DFIG voltage control capability during grid faults affects the performance of the active stall wind farm located in vicinity.

In each simulation a severe three phase short circuit grid fault is considered to happen in the transmission grid at the end of Line 4 close to the wind farms - see Figure 6. The grid fault lasts for $100 \mathrm{~ms}$ and gets cleared by permanent isolation (tripping the relays) of the faulty line (Line 4 in Figure 6). Note that, by tripping Line 4, the power system becomes weaker (higher impendance) and some components (e.g. Line 3 ) are fully loaded.

As the on-land wind turbines do not have any ride-through control implemented, it is assumed that they are disconnected from the system by their protection system, in the moment of the grid fault. In the moment of the disconnection, it is also assumed that the frequency stability in the grid is assured by large generator inertia.

The following scenario is common for the both simulations. In the moment of the grid fault, a voltage drop occurs. Immediately after the fault, when the rotor current magnitude is above the current protection limitation, the crowbar protection system of the DFIG is triggered, the rotor is short circuited, the RSC is blocked and the GSC operates as STATCOM. The damping controller starts to damp the drive train oscillations caused by the fault. When the fault is cleared and the DFIG wind farm terminal voltage recovers to a certain value, the crowbar protection is disabled, the RSC starts to control the grid voltage and the GSC is again set to be reactive neutral.

\subsubsection{DFIG voltage grid support capability}

In order to illustrate the DFIG voltage grid support capability, a worst case for the voltage stability is considered. It is assumed that, the $165 \mathrm{MW}$ offshore active stall wind farm, placed in the vicinity of the DFIG wind farm has its power reduction control disabled. This fact has a negative influence on the voltage stability in the grid, as the generator speed oscillations of the active stall wind turbine caused by the grid fault are directly reflected in the grid voltage.

Figure 7 illustrates the voltage, the active and the reactive power of the DFIG wind farm in the wind farm terminal (WFT), for the situations with and without DFIG voltage grid support respectively.

As expected, the influence of voltage grid support is visible both during grid fault, when the GSC operates as STATCOM and supplies reactive power after the disconnection of the crowbar, namely when the RSC controls the voltage on the grid. When no DFIG voltage grid support is enabled, the grid voltage oscillates as expected. After a while, it stabilizes to a higher voltage level. This aspect can be explained both by the reactive power surplus existent in the system as result of the on-land wind turbines disconnection and by the fact that, as result of the fault clearance (tripping Line 4), the transport of the active power from the wind farms to the grid is done through a higher resistance transmission line.

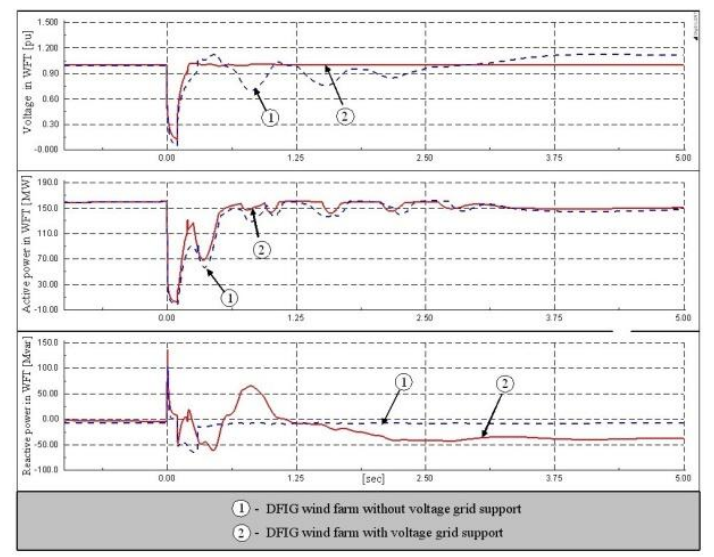

Figure 7: DFIG wind farm terminal with and without voltage control when the power reduction of the active stall wind farm is disabled.

Figure 7 shows that the existing reactive power surplus in the system is absorbed by the DFIG, when the voltage grid support control is enabled. Note that the DFIG voltage control re-establishes the grid voltage to 1p.u. very quickly without any fluctuations. No significant effect of the voltage control appears on the active power production. However, there it is a slight improvement in active power when voltage control is used. The small "drops" in the power, visible in both cases just after the fault is cleared, are generated by the damping controller used to damp torsional oscillations in the generator speed of the DFIG after the grid fault. Similarly to Figure 4, these oscillations are damped over few seconds. The initial level of the active power is reached after few more seconds.

\subsubsection{DFIG grid support capability effect on nearby wind farm performance}

The goal of the following simulation is to illustrate how the DFIG wind farm (DFIG-WF) voltage grid support control influences the performance during a grid fault of a nearby active stall wind farm, placed as illustrated in Figure 6. The next two figures contain therefore only information concerning the nearby active stall wind farm (AS-WF) during the 
grid fault, namely the active and reactive power in the wind farm terminal, the generator speed and the mechanical power of the active stall wind turbines, respectively.

The four following control sceneries are illustrated:

a. DFIG-WF without voltage grid support control and AS-WF without power reduction control.

b. DFIG-WF with voltage grid support control and AS-WF without power reduction control.

c. DFIG-WF with voltage grid support control and AS-WF with power reduction control.

d. DFIG-WF without voltage grid support control and AS-WF with power reduction control.

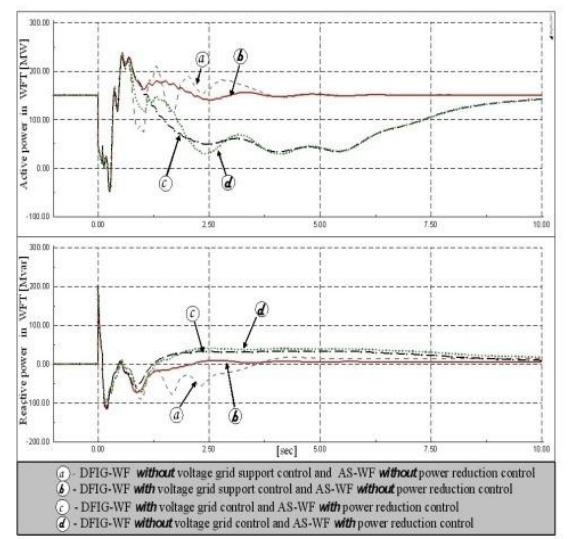

Figure 8: Active and reactive power of the active stall wind farm (AS-WF) in different situations.

The following observations can be made:

- The voltage grid support control of the DFIG wind farm (case $(b)$ and $(c)$ ) has a damping effect on the active stall wind farm, no matter whether this has or does not have power reduction control.

- The active power, the generator speed and the mechanical power are almost identical during the grid fault, no matter which case is simulated. The fact that the mechanical power is unchanged in this period means that the drive train system is equally stressed in all four cases.

- The worst case for the active stall wind farm is clearly the case (a), when the DFIG wind farm has no voltage grid support control and the active stall wind farm has no power reduction control.

- The best case for the active stall wind farm is clearly the case (b) (and not case (c)!), when DFIG wind farm is equipped with voltage grid support control, and the power reduction control of the active stall wind farm is not enabled. Note that, in case $(b)$, the AS-WF is not subjected to torsional oscillations and there is no loss in the active power production. The influence of the DFIG voltage grid support control on the active stall wind farm is thus even better when the latter does not have any special control implemented to overcome a grid fault.

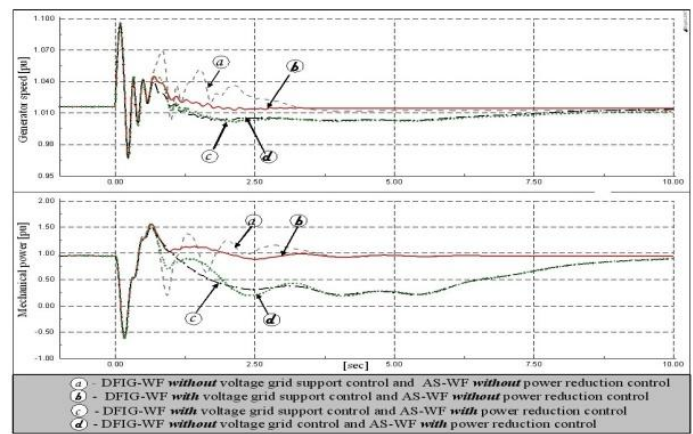

Figure 9: Generator speed and mechanical power of the active stall wind farm (AS-WF) in different situations.

The overall conclusion from Figure 8 and Figure 9 is that the DFIG wind farm equipped with voltage grid support control can help and improve the performance of a nearby active stall wind farm through a grid fault, without any need to implement an additional fault removing control strategy in the active stall wind farm.

\section{CONCLUSIONS}

This paper presents a voltage grid support control strategy for DFIG wind turbines, which enhances the fault removing and the voltage grid support capability of DFIG wind turbines during grid faults. The idea of this strategy is that both DFIG converters participate in the voltage control in a co-ordinated manner. By default, the grid voltage is controlled by the rotor-side converter as long as this is not blocked by the protection device (i.e. crowbar) otherwise the grid-side converter is taking over the control of the voltage.

The controllability of the DFIG during grid faults is enhanced by the design of a proper co-ordination of three additional controllers, such as damping controller, rotor-side converter voltage (RSC) controller and grid-side converter (GSC) reactive power boosting. The idea of the damping controller is based on the fact that grid faults cause torsional oscillations and high mechanical stress in the wind turbine's drive train. These oscillations are transmitted uncontrolled to 
the generator speed if the active power reference for the RSC control is defined as in normal operation, namely based on MPT look-up table. A way to damp these oscillations is to generate an active power reference as output of a damping controller. Such a controller has to be tuned to damp actively the torsional oscillations excited in the drive train system. The RSC voltage controller controls the grid voltage as long as the RSC is not blocked. The GSC reactive power boosting controller contributes with its maximum reactive power capacity in case of severe grid faults.

The DFIG wind farm fault overcoming capability and its contribution to voltage control is assessed and evaluated by means of simulations with the use of a generic but realistic transmission power system model in the power system simulation toolbox MATLAB (Simulink ).The DFIG wind farm is modeled based on aggregation approach, i.e. as one DFIG turbine with re-scaled power capacity. The simulation results illustrate how the DFIG wind farm equipped with the presented voltage grid support control strategy participates to re-establish properly the voltage during a grid fault. The influence of such a control setup on the performance of an active stall wind farm placed nearby is also investigated. The conclusion is that the DFIG wind farm equipped with voltage grid support control can help a nearby active stall wind farm to remove a grid fault, without implementation of any additional fault removing control setup in the nearby active stall wind farm.

\section{REFERENCES}

[1]. "Wind turbines connected to grids with voltages above $100 \mathrm{kV}$ - Technical regulations for the properties and the control of wind turbines,, Energinet.dk, Transmission System Operator of Denmark for Natural Gas and Electricity, Technical Regulations TF 3.2.5, 2004, 35 p. Available: www.energinet.dk

[2]. E.ON. Netzanschlussregeln Hoch-und Hoechst-spannung. 2003, Report ENENARHS2006, April 2006, 46 pages, www.eon-netz.com

[3]. Hansen A.D., Jauch C., Sørensen P., Iov F., Blaabjerg F. Dynamic wind turbine models in power system simulation tool DIgSILENT, Ris $\varnothing-\mathrm{R}-1400(\mathrm{EN}), 2003$.

[4]. Leonhard W. Control of electrical drives, Springer Verlag, 2001, ISBN 3540418202.

[5]. Hansen A.D., Hansen L.H., Wind turbine concepts market penetration over ten years (1995 to 2004), Wind Energy, No. 10, 2007, pp.81-97.

[6]. Hansen A.D., Michalke G., Sørensen P., Lund T., Iov F. Co-ordinated voltage control of DFIG wind turbines in uninterrupted operation during grid faults, Wind Energy, No. 10, 2007, pp. 51-68.

[7]. Hansen A.D., Sørensen P., Iov F., Blaabjerg F. Centralised power control of wind farm with doubly fed induction generators, Renewable Energy, 2006, vol. 31, pp 935-951.

[8]. Akhmatov V., Analysis of dynamic behavior of electric power systems with large amount of wind power, $\mathrm{PhD}$ thesis, 2003, Ørsted DTU.

[9]. Heier S. Grid Integration of Wind Energy Conversion Systems, John Wiley\&Sons, Ltd. Chichested UK, 1998.

[10]. Hansen A.D., Michalke G., Fault ride-through capability of DFIG wind turbines, Renewable Energy, vol 32, 2007, pp 1594-1610 .

[11]. Akhmatov V., Variable-speed wind turbines with doubly fed induction generators. Part II: Power System Stability. Wind Engineering, Vol. 26, No. 3, 2002, pp 171-188.

[12]. Akhmatov V., Variable-speed wind turbines with doubly fed induction generators. Part IV: Uninterrupted operation features at grid faults with converter control coordination. Wind Engineering, Vol. 27, No. 6, 2003, pp 519-529.

[13]. Sørensen P., Bak-Jensen B., Kristiansen J., Hansen A.D., Janosi L., \& Bech J. Power plant characteristics of wind farms. Wind Power for the 21 Century. Proceedings of the International Conference, Kassel, 2000, 6pp.

[14]. Eping C., Stenzel J., Poeller M., Mueller H., Impact of Large Scale Wind Power on Power System Stability, Fifth International Workshop on Large-Scale Integration of Wind Power and Transmission Networks, Glasgow, 2005, 9pp.

[15]. Kayikci M., Anaya-Lara O., Milanovic J.V., Jenkins N., Strategies for DFIG voltage control during transient operation, CIRED, $18^{\text {th }}$ Int. Conference on Electricity Distribution, Turin, 2005, 5pp.

[16]. Akhmatov V., A small test model for the transmission grid with a large offshore wind farm for education and research at Technical University of Denmark., Wind Engineering, vol.30, No. 3, 2006, pp. 255-263. 